\title{
UCHKUS: UN ESTABLECIMIENTO INCA EN HUANCAVELICA
}

\author{
Arturo Ruiz Estrada
}

Sumilla:

El papel de la administración incaica en el establecimiento del complejo arqueatbgico de Uchkus y, ol impocto de/ grado de influencio del estilo inca en la arquitectura y la affareria en una sociedad local, son analizados en este articulo.

\begin{abstract}
:
The Ince administration on the archaeological selttement of Uchkus, and the degree of impect of the Ince style in the architectural planning and local pottery are analysed in this paper.
\end{abstract}

\section{INTRODUCCIÓN}

Las diversas provincias del actual departamentode Huancavelica conservan en su territorio numerosos monumentos arqueológicos, la mayoría de ellos aún oficialmente desconocidos, aunque, sin duda, los habitantes locales tienen un conocimiento secular de ellos. Tales vestigios constituyen la evidencia del poblamiento prehispánico de la zona, por sociedades muy antiguas que fueron adecuando a sus necesidades los diversos ambientes que encontraron, de fuerte contraste altoandino, logrando así mejores niveles de subsistencia.

El estudio de tales grupos humanos, a través de los restos materiales de su cultura, es cada vez más urgente y necesario, por cuanto están sometidos a un proceso destructivo, cuyos efectos restringen paulatinamente el conocimiento de la historia real de nuestros pueblos. En ese sentido, ofrecemos ahora una aproximación inicial al reconocimiento de los bienes arqueológicos de Uchkus, cuya importancia radica en el hecho de ser uno de los centros representativos de la ocupación prehispánica de Huancavelica durante una época definida de desarrollo de la civilización andina, cuando el estado Inca dominó aquella región. En efecto, el complejo arqueológico de Uchkus y los diferentes sectores que lo integran reflejan, claramente, la expansión imperial del Tahuantinsuyo en Huancavelica y, al mismo tiempo, la instalación de un núcleo extranjero en el área ocupada por la antigua etnia Angara.

La investigación integral de Uchkus puede contribuir a una mejor explicación de los cambios ocurridos al interior de las sociedades locales por efecto del impacto incaico y podrfa ofrecer datos sobre el funcionamiento de un centro administrativo del
Tahuantinsuyo, en el contexto de similares establecimientos distribuidos en la sierra central del Perú. Asimismo, puede permitimos distinguir las expresiones materiales en aspectos como la arquitectura y la alfarería del estilo Inca, manufacturados en un área provincial y el grado de asimilación que pudo ocurrir en la tradición local.

Uchkus no es el único caso que expresa la presencia Inca en la zona, por cuanto ya otros investigadores han señalado sus huellas en otros lugares de Huancavelica (Soto y Macedo, 1936; Matos, 1959,1960 y Lavallé, 1973). Creemos, por eso, en la importancia del estudio del complejo de Uchkus, pues dispondremos de un nuevo hito para el entendimiento del complejo proceso prehispánico en la zona.

La historia de la sociedad Inca en el territorio andino ha sido registrada desde las primeras fuentes escritas por los españoles, pero los estudios arqueológicos realizados por investigadores modemos aportaron las expresiones materiales complementarias para su mejor comprensión. A parte de las publicaciones de viajeros y estudiosos no especializados, los trabajos pioneros de John Rowe (Rowe, 1944 y 1946) inician un estudio más preciso de la naturaleza del Estado Inca, al investigar las propias evidencias arqueológicas, como los monumentos arquitectónicos y los objetos de alfarería y, a partir de ellos, establecer la respectiva correlación con los datos ofrecidos por los cronistas de la conquistz. Con esos trabajos y luego de medio siglo de numerosas investigaciones de otros arqueólogos, se viene conociendo cada vez mejor la situación del desarrollo de la sociedad Inca en los Andes. Existe también buena cantidad de publicaciones sobre centros incaicoserigidos fuera del Cusco y su entomo inmediato. Dichos trabajos explican aspectos importantes de la

Aruro Ruiz Estorda. Profesor principal del Departamento de Aqqueologfa de la Universidad Nacional Federico Villarreal. 


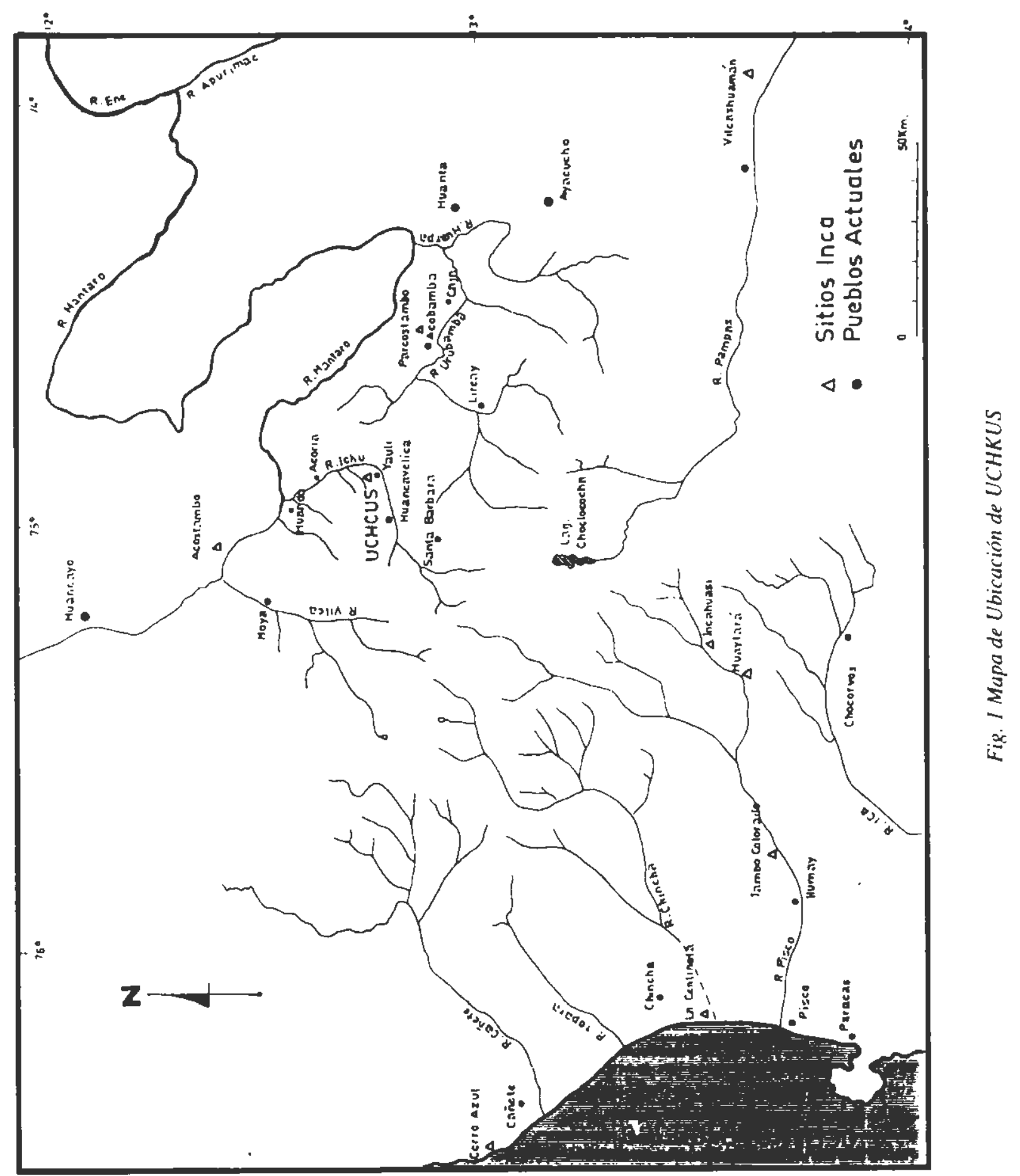


naturaleza expansionista y el carácter de la formación socioeconómica Inca, En tal sentido, el estudio de los monumentos de Uchkus y sus resultados constituirán nuevos aportes en el documento del proceso histórico ocurrido en la sierra central del Perú, durante la vigencia del Tahuantinsuyo.

Debido a la naturaleza exploratoria de la investigación, queremos llamar la atención acerca de las características y la antiguiedad del asentamiento, con la intención de generar el interés por estudios de mayor amplitud que puedan explicar, con datos más precisos, los diversos aspectos del funcionamiento y el rol que cumplió el sitio en la época de su vigencia. De igual manera. no debe perderse de vista la necesidad de su conservación y defensa, orientada a la puesta en valor de los monumentos, cuyos resultados tiendan, en alguna manera, al mejoramiento económico de la actual comunidad campesina de Uchkus.

La presente publicación se basa en un primer informe remitido al Instituto Nacional de Cultura de Huancavelica (Ruiz, 1995) luego de una visita inicial y preliminar, realizada en el mes de noviembre de 1994.

\section{UBICACIÓN Y ACCESO}

Uchkus, desde el punto de vista político administrativo actual, constituye un anexo $y$, al mismo tiempo, una comunidad situada en el distrito de Yauli, provincia y departamento de Huancavelica, Peń. Ocupa terrenos localizados sobre la margen izquierda del río Ichu. cubiertos por un manto vegetal de gramíneas conas, aprovechables para la cria de ganado nativo, como llamas y alpacas; ganado ovino, especialmente y, más limitadamente, vacuno. Algunos sectores del territorio comunal son utilizados para el cultivo de tubérculos andinos tales como papa y oca, entre otros, y de cebada. El clima es seco y frio con alturas que promedian entre $\operatorname{los} 3500$ a los 4000 metros sobre el nivel del mar.

En términos generales, la topografía es accidentada. con quebradas profundas y estrechas que discurren abruptamente en la encajonada cuenca del rio Ichu. Este río se origina en las alturas del distrito de Huancavelica, donde están los límites con la provincia de Castrovirreyna, a partir de los deshielos y filtraciones que ocurten en la vertiente oriental del paso de Chonta, próximo al sistema de lagunas de Choclococha. Luego pasa por la ciudad de Huancavelica, atraviesa la parte central del distrito de Yauli y es aqui la fuente hrdrica más importante. En este sector se incrementan sus aguas con el aporte de varios riachuelos muy torrentosos, entre los que destacan el Mashuaragra, por la margen derecha, y el Huanqapallqa y otros menores, como el Huaychao, por la margen izquierda. Finalmente, el rfo lchu desemboca en el distrito de Mariscal Cáceres, en la margen derecha del río Mantaro. Su recorrido entre los distritos de Huancavelica y Yauli abarca tres zonas ecológicas diferenciadas: la puna, con altos nevados, lagunas y pajonales, donde aparecen estancias para la ganaderfa de camélidos andinos, además de centros mineros importantes; la zona quechua alta, con laderas pronunciadas, donde es posible el cultivo de tubérculos nativos y la zona quechua propiamente dicha, con presencia de sembríos como el mafz, además de los tubérculos y algunos frutales. El anexo de Uchkus y el ambiente donde se encuentran los monumentos arqueológicos, por sus características climáticas y altitudinales, están comprendidos en la zona intermedia entre la puna y la región quechua.

Si tenemos en cuenta el área ocupada por la antigua etnia Angara, que comprendía desde la cuenca del rio Vilca y sus afluentes al Norte, hasta las cordilleras de Choclococha, al Sur y al Oeste, así como el espacio de las actuales provincias de Acobamba, Angaraes y Churcampa, se aprecia la ubicación central y estratégica de Uchkus.

El acceso al lugar toma como punto de partida la ciudad de Huancavelica, de donde se va por la carretera hasta el paraje de Sachapiti. De aquí, sólo hay una trocha para vehiculos de doble tracción con los cuales se llega al sector alto del anexo de Uchkus. Luego se utiliza un sendero que pasa por entre las casas actuales de los comuneros, y por él se llega al complejo arquitectónico antiguo. Otra nuta sale del pueblo de Yauli, punto de la vfa del ferrocarril Huancayo-Huancavelica, del cual parte un camino de hetradura en constante ascenso, ofreciendo más dificultades. De Uchkus se dirigen varios caminos tradicionales a numerosas comunidades y pueblos huancavelicanos.

Los pobladores se hallan organizados bajo el régimen comunal, úpico de altura, con un acentuado desenvolvimiento de la vida rural, cuya subsistencia económica proviene de la explotación agricola y de la ganadería en pequeña escala. Poseen un centro educativo mixto que imparte a la población escolar, la educación oficial peruana. De acuerdo a la Ley N¹4164, de fecha 23 de junio de 1967, Uchkus, junto a los anexos de Ambato, Chopja, Pachjlla, Caruac, Atalta, Chacarilla, Troya, Musojcancha, Matipacana, Tantajato y Parjacancha, pasaron a integrar el nuevo distrito de Yauli en la provincia peruana de Huancavelica.

\section{NATURALETADE LOSRESTOS}

Durante nuestra exploración pudimos apreciar en el lugar, las siguientes clases de evidencias arqueologicas: restos arquitectónicos, a]farería fragmentada en superficie y una figura tallada sobre la roca natural. La descripción de estos elementos nos faculta para ofrecer, por el momento, una primera 
aproximación sobre la naturaleza del complejo arqueologico. Hemos recorrido el sitio $y$, al mismo tiempo, obtuvimos mediciones, dibujos y fotografías. No realizamos excavación alguna, pero notamos que en dos sectores principales con arquitectura se hablan hecho excavaciones clandestinas; hecho por alguna persona que escombró muros semienterrados para saquear objetos antiguos. Esta acción ha puesto en peligro al conjunto monumental, por cuanto los sillares pétreos de la fábrica podrian desaparecer, peor aún, ya algunos bloques se hallan fuera de su contexto.

De acuerdo a las observaciones preliminares, y teniendo en cuenta la primera evidencia arqueológica identificada, esto es la arquitectónica, el complejo de Uchkus comprende tres sectores definidos y cada uno posee rasgos pariculares debido a ta naturaleza de las edificaciones y a su distribución espacial, hecho que permile aproximarnos al conocimiento de las funciones de cada sector en el tiempo de su vigencia.

El primer sector examinado es conocido tradicionalmente con el nombre de Qorimina. Se accede a él después de pasar por el núcleo actual de la comunidad de Uchkus. El segundo sector está separado del anterior por la quebrada de Uchkus o Qoriminahuaijo, y se denomina Tucolemisa, que es el conjunto central, al cual se le ha venido llamando Incañan, como consecuencia de una linderación de terrenos, en tiempos modernos, por funcionarios gubernamentales. El último sector, llamado Chuncana, se halla en una pequeña cumbre, después de Tucolemisa y siempre en la margen derecha de la quebrada de Qoriminahuaijo. A continuación, presentaremos los rasgos generales de los sitios mencionados.

\section{QORIMINA}

Son restos ubicados en una lomada pequeña sobre la margen izquierda de la quebrada de Uchkus, en cuya cima se aprecia, en primer lugar, una galeria cavada en la roca, a la cual se accede por medio de escalones tullados, que avanzan hasta unos $10 \mathrm{~m}$. Al pie de esta cima, frente a una pequeña explanada denominada Ocopampa, pero aún pegada al declive de la lomada. aparece un conjunto de estructuras rectangulares, entre muros de contención, por donde discurren canales. Un canal hecho de piedra, con sectores tallados en la propia roca, desciende de la parte baja del pago de Uchkus y se introduce al conjunto arquitectónico haciendo zigzag. Este canal se divide, al inicio, en dos pequefios canales y uno de ellos, en su tramo final, se vuelve a dividir en cuatro conductos angostos labrados en la roca. Justo al pie de esta roca aparece una oquedad, aparentemente natural, de unos $8 \mathrm{~m}$ de profundidad horizontal. Si la cquedad tiene un desplazamiento horizontal es un túnel, entonces, mejor diremos $8 \mathrm{~m}$ de longitud que de profundidad.
Todo el conjunto viene a dar a la explanada antes indicada, la cual culmina en la quebrada que divide los territorios de Uchkus y permite el acceso a los terrenos de Tucolemisa y Chuncana.

Las estructuras rectangulares de este sitio se hallan limitadas por muros de contención y tienen menores dimensiones que la estructura principal de Tucolemisa. Los bloques integrados a los muros adoptan, en general, formas rectangulares, labradas al estilo incaico, pero son más pequeños si los comparamos con los bloques utilizados en el sector central o Tucolemisa. El área ocupada por el conjunto no es muy extensa y no sobrepasa los $50 \mathrm{~m}$. Se observa en ella trabajos de escombramiento sin control arqueológico, ocasionando la dispersión de varias piedras del aparejo.

El nombre del sitio podría ser compuesto y derivarfa de las palabras Qori que significa oro en el idioma quechua y del término español mina, en alusión a la presencia de la pequeña galería mencionada. Sin embargo, en la zona de Huancavelica existen topónimos nativos como Laymina, Quimina, que no tienen relación con alguna explotación minera.

\section{TUCOLEMISA}

Es el segundo conjunto o sector central, al que se asciende desde la quebrada de Qoriminahuaijo. por la margen derecha. Está alejado del sector de Qorimina aproximadamente por unos $300 \mathrm{~m}$. Las estructuras aparecen entre parcelas cercadas de pirca modema, y se trata de construcciones rectangulares, semienterradas. conformadas por bloques de piedra tallados. Aquí sobresale nítidamente una portada todavía en pie. En general, todo el sector es denominado tradicionalmente como Tucolemisa y en él se hallan también varias construcciones modernas de los comuneros de Uchkus. En una de estas casas se observa cimientos con algunos bloques probablemente extraídos del conjunto arqueológico.

Actualmente, sólo son visibles cuatro recintos antiguos, en cuyo entorno se han hecho excavaciones clandestinas al lado de las paredes, sin control arqueológico alguno '.

Según la disposición en escuadra de los recintos, éstos habrian sido levantados alrededor de un espacio o atrio, no visible por la acumulación de tierra procedente de la destrucción ocurrida hace bastante tiempo, desde que la dejaron sus ocupantes. Para ofrecer esta descripción, hemos asignado letras a cada unidad. La estructura $A$, de mayor dimensión que las restantes, ubicada a Este del conjunto, mantiene visible la base de la pared oriental y los tramos iniciales de las paredes norte y sur; la pared oeste no aparece o, en todo caso, los cimientos podrían estar enterrados. 


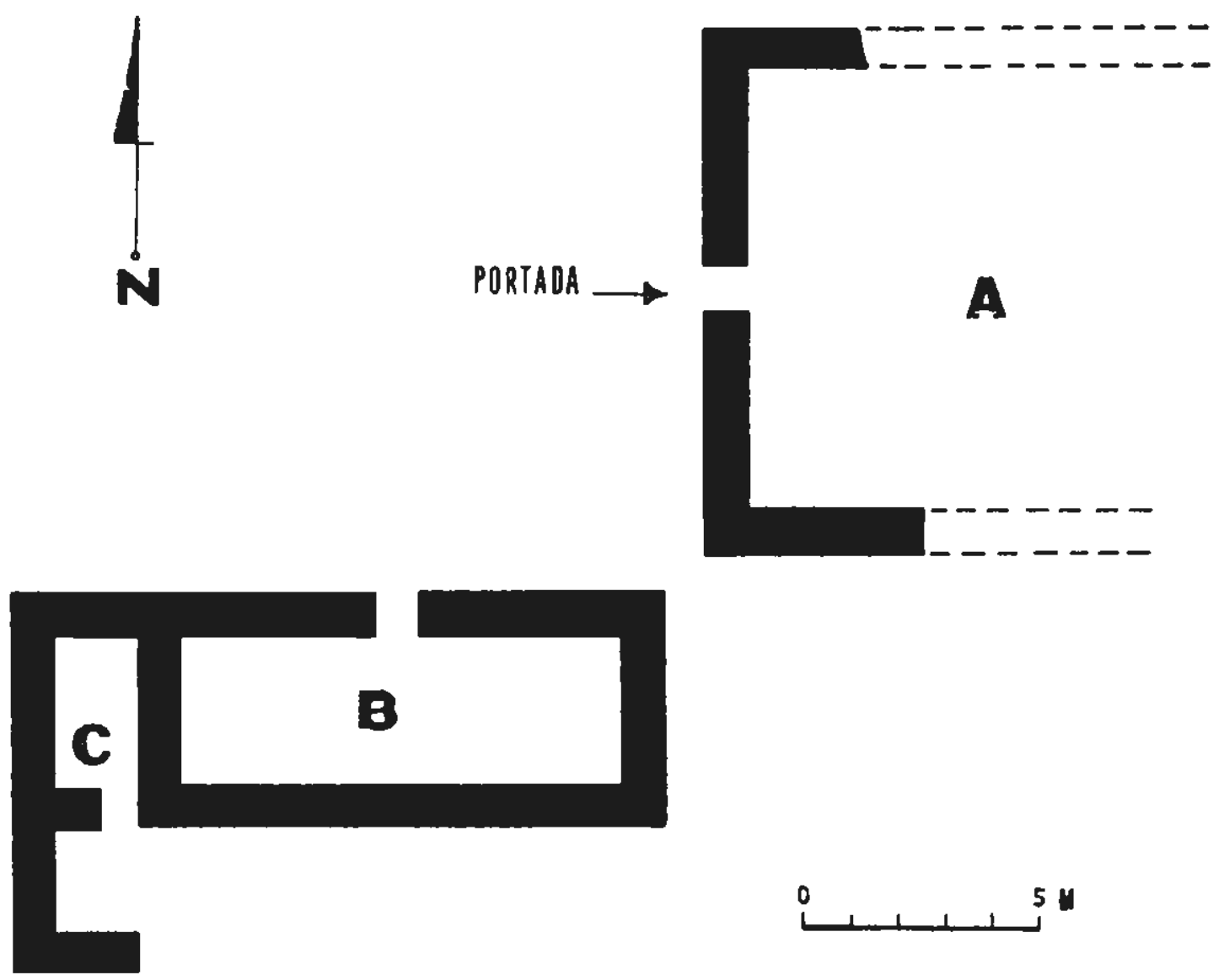

Fig. 2 Dibujo de planta de las estructuras descritas.

Un elemento arquitectónico destacable es la portada con jamba simple, cuyo dintel y umbral pernanecen intactos. El dintel se compone de dos bloques alargados: cl vano cs trapezoidal y, junto a] umbral, hay dos escalones de piedra hacia el exterior, aunque no se observa el piso. Los muros alcanzan $1 \mathrm{~m}$ de altura y los bloques presentan forma rectangular con tendencia de cuña: la cara cxterna de éstos es ligeramente ahombada y las junturas bicn ajustadas a la manera de las clásicas parcdes cusqueñas. Los litos fueron trabajados mediantc percusión regular y carecen de pulimentación. En términos generales, la construcción alcan $\angle a$ un ancho total de $11 \mathrm{~m}$; el tramo de la pared sur mide 4,44 $\mathrm{m}$ hasta donde es visible, pues no se sabe la extensión cotal a causa de no existir actualmente continuidad en dicho muro: el ancho de la parte superior Jel vano de la portada mide $0,64 \mathrm{~m}$ y el inferior tiene 0,83 $\mathrm{m}$; la altura total de la ponada es de $2,13 \mathrm{~m}$. Los bloques del dintel miden $1,31 \mathrm{~m}$ y $1,12 \mathrm{~m}$ de largo con $0,44 \mathrm{~m}$ y 0,36 $\mathrm{m}$ de ancho y $0,35 \mathrm{~m}$ de espesor.

La cstructura B, de similares características que cl cdificio anterior, es también de planta rectangular y sólo está separado de éste por un espacio de $1 \mathrm{~m}$; tiene puerta al lado norte. pero únicamente mantiene los cimientos. El largo alcanza $11 \mathrm{~m}$, el ancho es de $4.90 \mathrm{~m} \mathrm{y}$ el vano mide $0,82 \mathrm{~m}$ de ancho.
La estructura C, adyacente a $B$, posee una pared divisoria interna, con un vano que las comunica. La forma del recinto, su factura y la naturaleza de los elementos pétreos, muestra los mismos rasgos que el resto de edificios descritos. De largo mide $8 \mathrm{~m}$ y de ancho, 2,65 m. El primer recinto de esta estructura es más espacioso y tiene un largo de 4,90 m; en cambio el segundo mide 3,10 m.

Aparte de lo mencionado, no hemos apreciado otras estructuras antiguas; Ios referidos cercos de pircas y chacras son actuales y están distribuidos entre los muros arqueologicos. Tampoco se ven muchos bloques en las inmediaciones, como es usual observar en otros restos arqueológicos destrúfos, salvo los bloques colocados e. l los cimientos de una casa actual próxima al sitio.

\section{CHUNCANA}

Hacia la zona sur este de Uchkus, margen derecha de la quebrada, sobre una cumbre baja y algo plana, se halla el sitio de Chuncana, en posición más elevada que los sectores anteriores. Una distancia aproximada de no más de $300 \mathrm{~m}$ lo separa de Tucolemisa. Desde la cumbre se tiene una amplia visión de las cordilleras más alejadas que emergen sobre los distritos de Yauli y Acoria. 


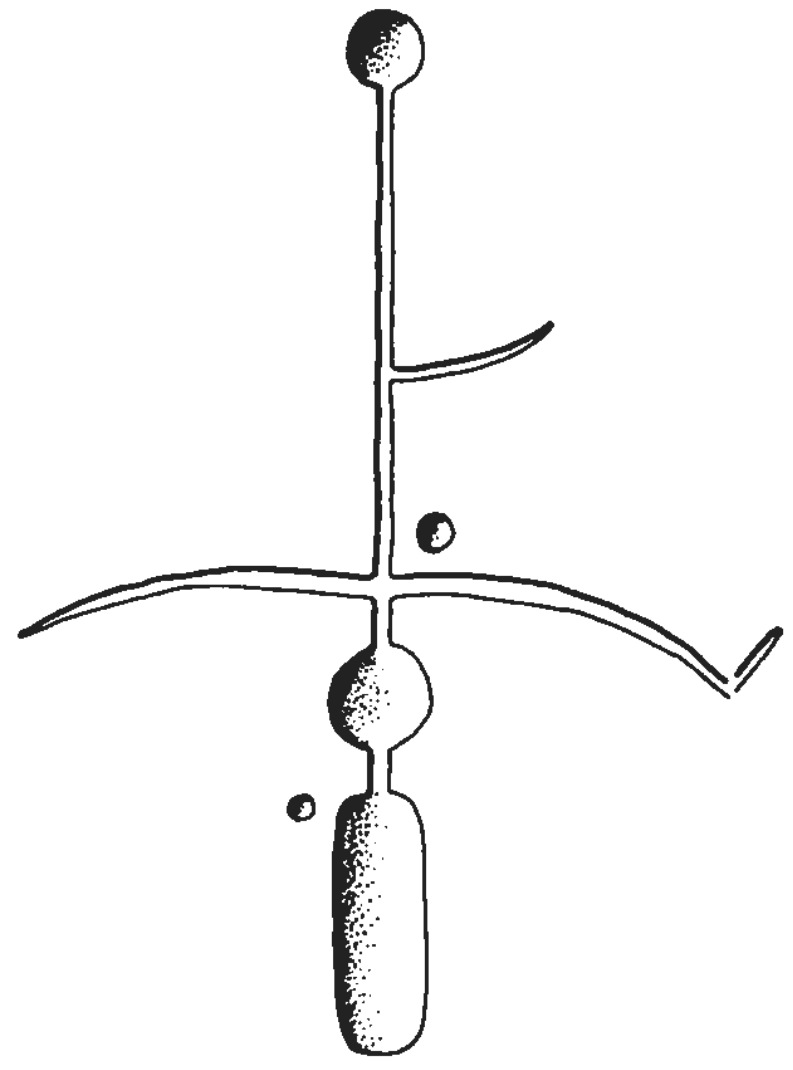

Fig. 3 Diseño en la roca de Uchkus.

La cima presenta una configuración más o menos plana con fueres declives hacia el oeste. Es de naturaleza rocosa y forma un espacio definido por algunos muros ubicados hacia el perimetro. En la parte central de este aparece una figura geométrica tallada en el piso, a manera de un gran perroglifo, cuyas dimensiones alcanzan aproximadamente un largo de $7,19 \mathrm{~m}$, con un ancho total de $5 \mathrm{~m}$ y una profundidad de las tallas que no excede los $0.15 \mathrm{~m}$. La figura está constituida por tres pequeños pozos centrales conectados por un canal angosto; dos de ellos son circulares y el del extremo es elíptico alargado. Más o menos de la parte media del canal, salen otros dos en forma curva. Dos pozos diminutos, también circulares, flanquean el canal central (Fig. 3).

\section{G.ALFARERIA}

Se trata, en general, de fragmentos procedentes principalmente de la superficie del sector Tucolemisa. Entre los bordes de esos fragmentos se distingue, en orden a su mayor frecuencia, lo siguiente:

1. Alfareria Llana (50 fragmentos), sin decoración, de aspecto tosco y alisado simple, hecha con un instrumento que dejo huellas horizontales muy delgadas. Tiene la superficie rojiza y en menor porcentaje gris. La pasta, por lo común, es gris $y_{4}$ a veces, se presenta rojiza hacia la superficie. Se observan las formas siguientes:

a) Cántaros de cuello corto de paredes divergentes, labio redondeado y cuerpo esferoidal (Fig. 4: a,b,c).

b) Cántaros de cuello corto, cuyas paredes son mís o menos verticales, labios redondeados con el sector superior del borde expandido (Fig. 4:d,e,f,g,h,i,j,k,l).

c) Cuencos de labio redondeado y cuerpo semiesferoidal (Fig. 4: $\mathrm{m}$ ).

2. Alfarería con Engobe Rojo (22 fragmentos), que a veces aparece engobado en una sola cara. No hemos identificado diseños decorativos. Por lo escaso de la muestra, no sabemos si este tipo, como el anterior, fue decorado o no. Más bien, se dan las mismas formas y pasta como en la Alfarería Llana.

3. Alfarerfa de Estilo Inca (4 fragmentos), con la superficie pilida y la pasta más fina que las anteriores, pero del mismo color. Se han identificado formas de aribalos y pucos. Un borde de aribalo tiene el labio pintado de color negro; la superficie interna muestra una banda ancha de color rojo y la superficie externa está cubierta con pintura roja. Otro borde, también de aríbalo, lleva una banda roja que cubre el labio y la parte superior de la cara interna. El fragmento de puco corresponde a un cuenco con pintura roja en el extremo superior de ambas superficies y en la cara interna lleva pintura crema. Un segundo fragmento tiene el borde y la cara intema pintada de color rojo (Fig. $4: n, 0$ ).

4. Alfarerfa decorada, que corresponde a un solo fragmento con superficie de color ladrillo en la que se ha pintado una línea de color blanco.

\section{DLSCUSIONES}

La actual provincia de Huancavelica en la cual está ubicado Uchkus, constituyó en el pasado una de las áreas pobladas por la antigua etnia Angara, de origen preinca; pe ‘o debemos anotar que este grupo habitó tambien en las modernas provincias huancavelicanas de Acobamba, Angaraes y Churcampa. La integraban las parcialidades o curacazgos Angara, Asto y Chaca (Jimenez de la Espada, 1881). Esos curacazgos incluían varios pueblos o ayllus que conformaban la base sobre la cual se erigla el gobiemo nativo. Es posible que haya sido un reino, cuyo territorio habría estado dividido en dos sectores, los Astos y los Chacas, con límites definidos. Asi se afima en un estudio sobre la presencia de mitmas entre los Angara, graficado incluso con un mapa (Espinoza Soriano, 1973); aunque si cotejamos dicho mapa, con la "Descripción de la Provincia de los Angaraes" (Jimenez de la Espada, 1881 : 140-144), parte de esos límites requieren una nueva demarcación, ya que se afirma en esa descripción que los pueblos de 
Huando y Acoria estaban en territorio Chaca y no en el de los Asto, como lo consigna dicho mapa. Ovo estudio, que toca a los Angara, expresa que hubieron los Hanan Angara y los Hurin Angara (Lavallee, 1983), pero la fuente a que se alude no indica esa división, aunque ésta pudo existir, puesto que así se reconocía para grupos vecinos de los Angara, como los Yauyo, los Huanca y otras comunidades prehispánicas. En el periodo colonial hispánico, los pueblos Angara integraron políticamente diferentes repartimientos $y$, en lo eclesiástico, formaron cinco doctrinas: Lircay, Julcamarca, Acobamba, Conaica y Acoria (Jiménez de la Espada, 188 1:140-144). La palabra Angara pudo derivar del término quechua Anga o Anca cuyo significado es el de águila, según el Lexicón de Fray Domingo de Santo Tomás (1560). Los españoles la pronunciaron como Angara o Angaraes. Se ha mencionado también que esa palabra proviene del término Ancara, con el significado de plato grande de calabaza (Espinoza, 1973:10). El auge de estos pueblos se habría dado en el periodo Intermedio Tardío (Siglos X al XV d.C.), después del colapso de las influencia iniciales de Huarpa y Caja, y posteriormente de las de Huamanga y Viñaque, correspondiendo éstas últimas, a las expresiones de sociedades que tuvieron fuerte presencia en el área de Ayacucho durante el Horizonte Medio (Siglos VI al X d.C.).

Un aspecto importante del área poblada por los Angara es el estar ubicada en una región intermedia que comunicaba varias etnias situadas en la costa, sierra y ceja de selva. Su territorio limitaba con el de las etnias Huanca, Yauyo, Chocorbo, Chincha y Chanca, pueblos con los que mantuvo cercanas vinculaciones culturales. Es también posible que los Angara tuvieran algún tipo de contacto con las poblaciones asentadas en la cuenca del río Ene y en las montañas de Satipo.

Se comprende, además, la importancia del área de Uchkus si tenemos en cuenta que desde varios milenios previos a la consolidación de la entidad sociopolítica Angara, habfase instalado en la parte baja de este sitio, un singular centro ceremonial conocido como Atalla, cuya antigüedad se remonta al periodo Formativo, y que fue uno de los más destacados de la Sierra Central del Perú. Consiste de un templo con viviendas, posee alfarería muy fina vinculada con Chavín de Huantar (Matos, 1959) y la fase Janabarriu detectada en ese lugar (Burger, 1995,comunicación personal).

La ubicación de Uchkus muestra justamente la ocupación de un punto en la parte central del antiguo territorio de los Angara (Veáse el mapa sobre la distribución de esta etnia según Espinoza, 1973). Según Espinoza, esa área estaba dividida en dos mitades: Asto y Chacac y entre los pueblos principales adyacentes menciona, por ejemplo, al de Acoria. Se infjere, del referido mapa, que Uchkus estaba localizado al sur de este pueblo y, por ende, cerca al lindero de las mitades. de modo que estaria en territorio Asto. Pero, si tenemos en cuenta la distribución de los pueblos Angara, mencionada en la "Descripción de la Provincia de los Angaraes", hecha hacia 1586 (Jiménez de la Espada, 1881), se observa que el pueblo de Acoria y el de Huando figuran en la mitad Chaca y no en la de los Asto, por cuya razón, Uchkus estaría en suelo Chaca. En todo caso, pensamos que Uchkus fue construido en una zona limitrofe entre dichas parcialidades Angara, aunque dentro del territorio Chaca. En ese sentido, el rio Ichu, que corre al pie de las cumbres de Uchkus y tributa sus aguas al rio Mantaro por la margen derecha, viene a ser parte de esos límites. Esta ubicación fronteriza de Uchkus explicaría por qué los Incas decidieron establecer allf un eje administrativo, como parte de la estrategia geopolítica en cuanto al control e imposición sobre los Asto, Chaca y los propios Angara.

La estrategia política de los Incas, aplicada a la región Angara, se tradujo en la ejecución de acciones diferentes, que estuvieron en directa relación con el panorama social que presentaba cada curacazgo integrante de esa etnia. Las observaciones realizadas por Daniele Lavallé aclaran algunos aspectos de] impacto Inca en la sociedad local, especialmente en el curacazgo Asto (Lavallée, 1983). De acuerdo a lo informado sobre los Asto y la provincia de los Angaraes, los gobernantes cusqueños procedieron a trasladar masivamente a los Angara del sector Sur Este o del grupo Hanan Angara, como los denomina Lavallée, situación que nos hace pensar que tal mandato debió estar en relación con la mayor resistencia que opusieron éstos, a pesar de poseer los recursos, particularmente agrícolas, más productivos que la de los Asto o Angara del sector norte. Paralelamente, la gestión Inca introdujo varios grupos de mitmas en la totalidad del territorio Angara. Entre los Asto, del que no se conocen deportaciones, se menciona que hubo un ayllu incaico en la localidad de Cuenca y otro en Huando en el sitio de Rockcha (mitad Chaca). Es en este sitio, sin embargo, donde existe clara evidencia arqueológica de la ocupación Inca, pues “gran parte del equipo cerámico encontrado en las viviendas era de estilo cusqueño"(Lavallé, 1983:38). Pero donde se encuentra el mayor número de mitmas es en el sector sur este del área Angara, que habria sido el asiento del grupo Hanan Angara para Lavalke. Probablemente, fieles a la tradición local de ser los más valerosos y esforzados del reino y que tenfan a los Incas en constantes guerras, los Hanan Angara no se allanaron fácilmente al dominio imperial del Cusco. Aqul estuvieron presentes por compulsión varios enclaves extranjeros, trasladados por los Incas en tiempos de Huayna Capac. De este modo, se pobló el sitio de Caja con indios Quiguares orejones del Cusco, quienes habrían detentado el poder Inca en esa zona. Los pueblos de Acobamba y Andabamba con nativos Guaros de Huarochirí; los pueblos de Lircay, Huchuiguaillay, Angaraes, Atunguaillay, Huancahuanca, Congalla y Julcamarca con mitmas Chancas de 

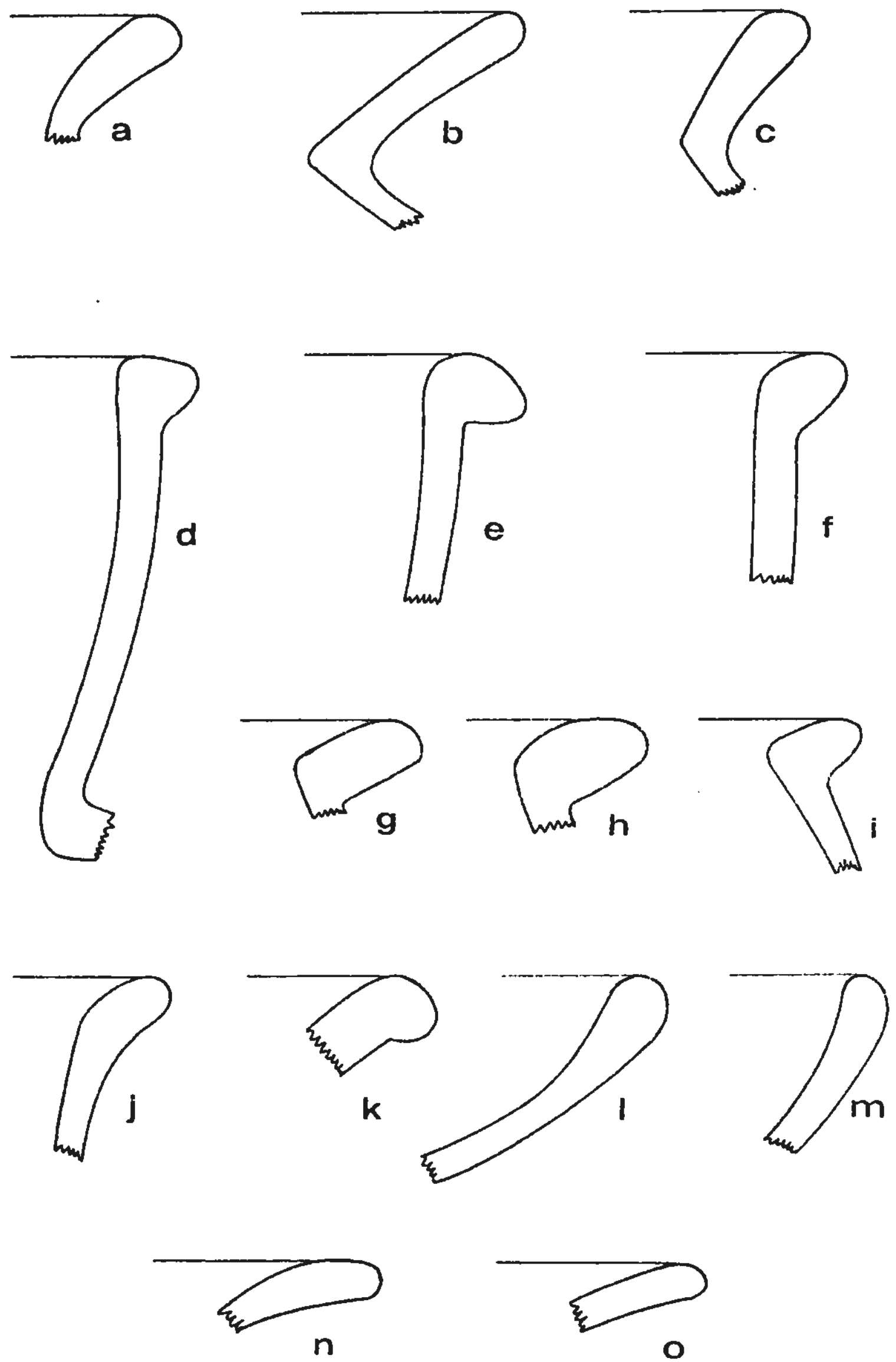

Fig. 4 La alfarería de Uchcus. 
Andahuaylas; el pueblo de Callanmarca con mitmas de Cajamarca (Jiménez de la Espada,1881), a los que se añadian los Cayampi del Ecuador, puestos en el pueblo de Matibamba para producir coca y, finalmente, se impuso a los Chachapoyas y Huamalíes de Huánuco en un lugar aún no identificado (Espinoza, 1973:11). Hubo pues, como se aprecia, una política agresiva que desestabilizó los ayllus Angara de ese sector.

Otra de las decisiones emanadas del Cusco fue la de construir un núcleo residencial en Uchkus, con varios sectores, bajo el propio diseño del estilo arquitectónico imperial. Como fue característica del estado Inca, su presencia tenia que hacerse ostensible entre el grupo dominado, incluso en expresiones como la alfarería y la arquitectura, símbolos del nuevo poder implantado.

Hasta el presente, no se ha identificado otro establecimiento de estilo Inca similar a Uchkus en el lerritorio Angara. El sitio de Parcostambo, en la vecina provincia de Acobamba, si bien es de la misma época, no tiene la complejidad de Uchkus y se trata, según lo conocido al presente, sólo de una posada o tambo, del cual se nota únicamente los cimientos de una estructura rectangular, ubicada en la parte principal del camino real que unía Vilcashuamán con Picoytambo, Acostambo y Jauja. Tampoco hasta hoy se ha informado si en Caja existe un sitio incaico. Esta situación sugiere que los Incas no fundaron un centro administrativo en el propio núcleo del poder Angara, que pudo haber sido al centro del territorio Asto o Chaca o el sector Sur y Este del espacio Angara, ubicándose más bien en el lindero entre estos grupos, posiblemente porque los Angara no se habian unificado. Quizá en ese tiempo no hubo un poder central con una capital desde donde los Incas pudieran articular su dominio, como sí ocurrió, por ejemplo, en el caso de los Chincha, cuando los gobernantes cusqueños se instalaron en un núcleo como La Centinela, sede del poder y gobierno centralizado de los chinchanos (Menzel,1967). Igual situación podría haberse dado en Pachacamac en tanto que, entre los Angara, el poder cusqueño debió impartirse desde una zona limítrofe y nueva, en un sitio sin antecedentes de ocupación nativa, como Uchkus, siempre y cuando éste sea el sitio principal y no Caja u otro. Cabe la posibilidad de la existencia de otros centros Inca, tal vez con diferentes niveles jerárquicos, de acuerdo al componamiento social que cada curacazgo haya tenido en su relación política con los Incas.

Además del control político, el interés cusqueño en la zona de Uchkus debió estar dirigido al aprovechamiento de los recursos económicos que poseían los Angara. En efecto, en su territorio había filones metálicos, especialmente en localidades próximas a Uchkus, como aquellas de la vertiente oriental y de las propias punas cordilleranas, que incluyen a
Choclococha, donde, hasta el presente, existen centros mineros de segundo orden. En esta zona se halla también importantes canteras de obsidiana y uno de los más abundantes emporios de mercurio, cuyo derivado tintóreo, el bermellón o "llimpi" fue sustancia muy apreciada por la sociedad andina. Además, no habría escapado a la óptica económica de esa época, la explotación de los pastizales para la ganadería de camélidos andinos, por ser éstos fuente de carne, lana y medio importante de transporte de carga. A ello debió agregarse el aprovechamiento de la fuerza de trabajo de los ayllus Angara, para el engrandecimiento del poder emanado del Cusco.

E] área de Uchkus, por otro lado, se hallaba ubicada en la ruta que unía la capital del Tahuantinsuyo con otros reinos norteños. Aunque no estaba precisamente en el camino real, se conectaba con él por un ramal que, al mismo tiempo, lo enlazaba con centros administrativos y tambos como los de Vilcashuamán (Ayacucho), Parcostambo (Acobamba), Picoytambo y Acostambo (Huancavelica) y el más distante de Huaytará. Fncontrábase pues enlazado a la red de sitios estratégicos edificados por los Incas, en el ámbito de la Sierra Central del Perú Antiguo.

La presencia de Uchkus en territorio hoy huancavelicano, por las condiciones anotadas y discutidas en esta sección, significa un asentamiento muy distinto a la mayoría de poblados prehispánicos tradicionales de la región, caracterizados por tener edificaciones de planta circular, como lo ejemplifica el caso de los Asto (Lavallée,1973) y que obviamente. difieren de las de Uchkus, donde sólo hay habitaciones de plano rectangular. Distunguimos esto con claridad al contrastar Uchkus con el cercano conjunto arqueológico de Pucara, ubicado en el mismo distrito de Yauli, margen derecha del rí Ichu, cuya distribución aglutinada con casas de planta circular responde a la tradición local y regional de núcleos Angara. Lo mismo se observa si confrontamos Uchkus con los citados establecimientos del territorio Asto, ocupados por el grupo norteño de los Angara, y distribuidos en los actuales distritos de Moya, Vilca, Huayllahuara, Pilchaca, Cuenca, Conaica, Manta, Laria y Ojoro, donde no hay injerencia del patrón arquitectón: co de estilo Inca (Lavallé, 1983:36). Cabe resaltar que desde el punto de vista arquitectónico, Uchkus muestra nítidamente la impronta del estilo cusqueño en el dominio de los Angara. En ese sentido todo parece indicar, a falta de otras evidencias arquitectónicas previas a la Inca, que el establecimiento de Uchkus no fue construído encima o al lado de otras estructuras tradicionales, sino que constituyó un asentamiento nuevo fundado en razón a los intereses del poder estatal cusqueño, como caso muy frecuente en la estrategia expansionista Inca. Se ha opinado que en la edificación de centros similares, no tenian en cuenta las condiciones productivas del sitio o que estos 


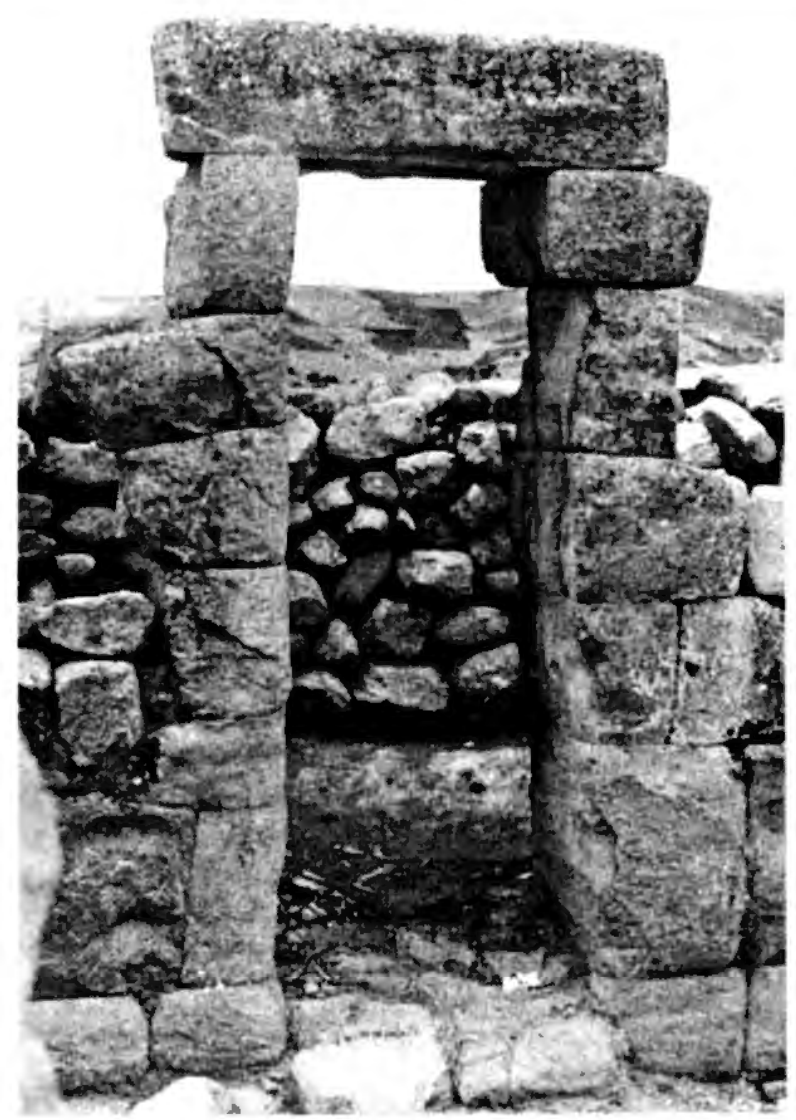

Fig. 5. Portada Principal.

dispusieran de baluartes militares, sino más bien centraron su atención en dar seguridad a los puntos de flujo de las acciones de conquista para la pacificación y sometimiento de poblaciones locales (Lavallée, 1983:26). Debemos pues pensar en las instalaciones de Uchkus como un centro impuesto en los límites de los sectores en que estaban divididos los pueblos Angara, Asto y Chaca y que, en el planteamiento acerca de este tipo de sitio, estariamos ante un establecimiento de carácter operativo para la política Inca (Morris,1973).

A pesar de ello, el sitio que discutimos ofrece ciertas condiciones ambientales que favorecen la construcción de un puesto de altura, asunto en el que debieron reflexionar los gobernantes Inca, pues la inversión en las acciones de pacificación y sometimiento implicaba seguramente el aprovechamiento de los excedentes dei grupo dominado. En efecto, de Uchkus se tiene buena visibilidad, tanto hacia la cuenca del río Ichu como a las cumbres rocosas que lo marginan. Las quebradas del entorno no debieron constituir, en esos tiempos, obstáculos insal vables, pero sí dificultosos para una posible incursión extraña. Existen, asimismo, arroyuelos de donde aprovecharon el agua para el sostenimiento de sus ocupantes, entre los que destaca la quebrada de Qoriminahuaijo, que escurre al río Ichu. Los terrenos del sector alto son aptos, hasta hoy, para el cultivo de tubérculos (papa, oca, mashua) y en ellos prolifera el pasto nativo, aprovechado para la crianza de ganado. En la parte baja, a orillas del río Ichu y avanzando hacia la zona de Acoria, el clima es más abrigado y tiene mejores condiciones para la agricultura del maíz y algunos frutales de altura. De igual modo, el ambiente climático de la zona, frígido y seco, no fue impedimento para que allí se fundara un poblado incaico, más aún si consideramos que los Incas procuraron priorizar los intereses del Estado, cuyo carácter expansionista desafió junglas, desiertos y punas muy altas, como lo demuestran las instalaciones de Pumpu (Junín), Huánuco Pampa (Huánuco), Cochabamba (Amazonas), Huancasragau (Alto Pativilca) y el Tambo de Huaura en Huacho (Lima), para citar sólo unos pocos ejemplos.

Los atributos estilísticos de la arquitectura, como la forma y el tratamiento de los bloques, la planta rectangular de los recintos, la presencia de canales tallados en bloques o en la propia roca, la portada con tendencia trapezoidal y la composición de aparejo de las obras, tanto Je Qurimina como de Tucolemisa, los sitúan dentro del estilo incaico. Estos detalles concuerdan con las características que se han dado para identificar otras edificaciones estatales del Tabuantinsuyo (Kendall,1976), en particular con asentamientos más próximos como Vilcashuamán y Huaytará, también construidos durante la expansión del Imperio. Pero si los comparamos en cuanto a determinadas características y magnitud, debemos advertir que estos centros revelan una categoría mayor, en la medida que poseen una albañilería muy esmerada y porque exhiben más complejidad en la distribución de los recintos que, al mismo tiempo, son más numerosos que los de Uchkus (Gonzáles Carré y otros, 1981). En efecto, Vilcashuamán conserva estructuras grandes; agrupa plazas, ushnu, templo, recintos de carácter militar, depósitos, viviendas y murallas que no se encuentran en Uchkus. De igual manera, el establecimiento de Huaytará destaca por el fino acabado de sus muros, por tener singulares hornacinas y nichos que naturalmente no están presente en Uchkus, aun cuando éste no haya sido estudiado integralmente. Tampoco Uchkus tiene punto de comparación, en cuanto a la extensión, con Huánuco Viejo o el centro administrativo de Pumpu, donde recientes estudios muestran la gran complejidad interna y la vasta dimensión que alcanzó el conjunto (Matos,1994).

Por otro lado, si bien Uchkus refleja el dominio Inca entre los Angara, tiene al mismo tiempo particulares formas de adecuarse al medio geográfico. Qorimina fue construido en una ladera. Tucolemisa, en un espacio llano y Chuncana, en una cima a mayor altura. Esto indica la adopción de estrategias arquitectónicas diferentes en relación con el objetivo estatal y el medio donde les tocaba actuar, como ya se ha informado para estos casos, como por ejemplo en la construcción del conjunto de Ollantaytambo (Protzen, 1993). 


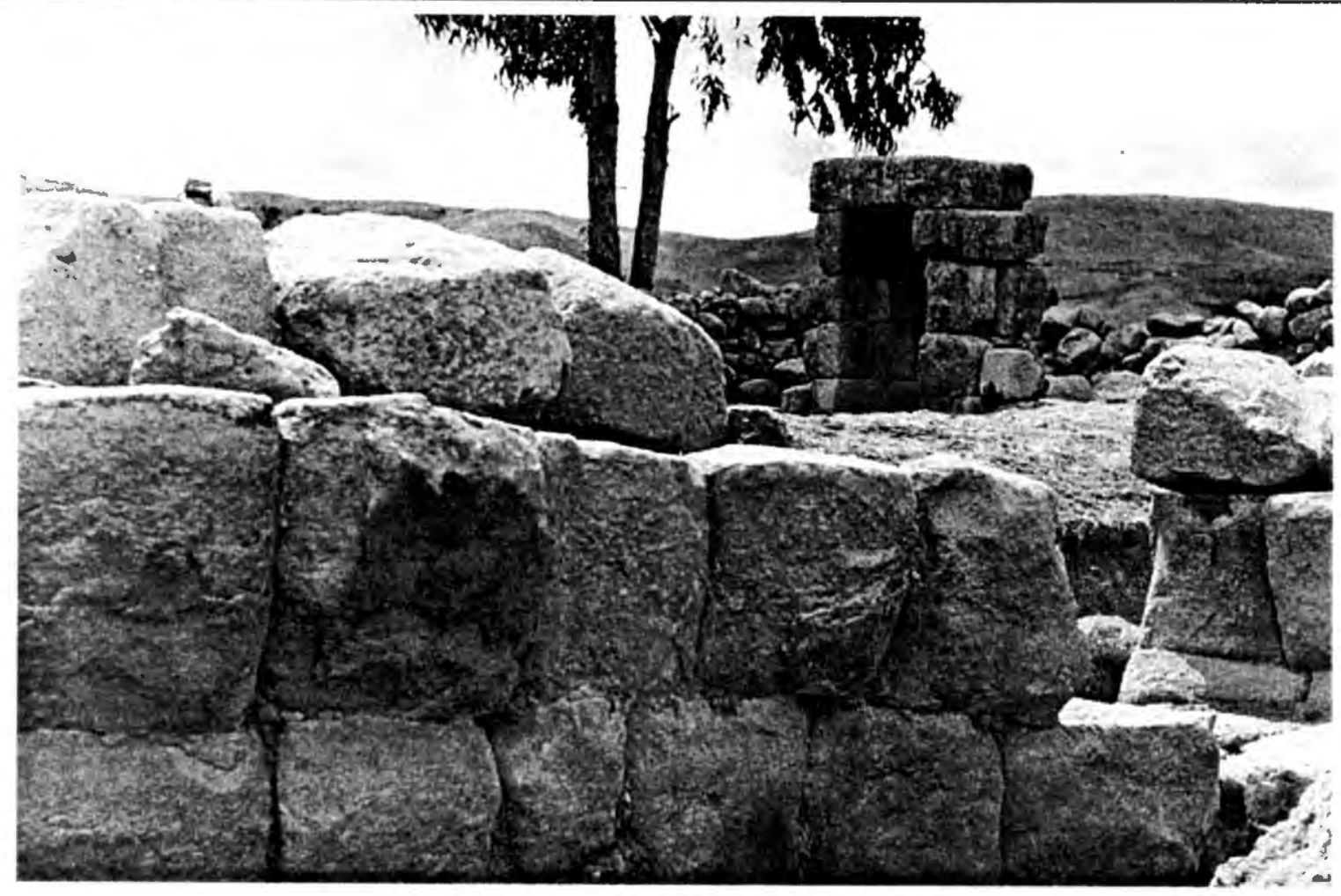

Fig. 6 Muro Inca y portada principal de Uchkus.

Se ha mencionado que Vilcashuamán fue construido durante el reinado del inca Pachacutec (Kendall, 1973:78), de modo que su crecimiento continuó en el reinado de sus sucesores. En cambio Uchkus, por ser más pequeño, con tres conjuntos separados pero cercanos, no muestra el desarrollo y complejidad de Vilcas, pues de haber sido edificado en tiempos de Pachacutec babría tenido que acrecentar sus instalaciones en años posteriores. Pensamos por ello, que Uchkus podría añadirse al conjunto de centros que ordenó construir su sucesor, Topa Inca Yupanqui, quizá para asegurar sus conquistas costeñas, toda vez que Uchkus, Huaytará, Incahuasi y el mismo Tambo Colorado habrían sido edificados para controlar no sólo a los grupos locales próximos, sino también al poderoso reino de los Chincha, en cuyas serranías están ubicados Uchkus y Huaytará.

Al observar la ubicación que tiene el sector de Qorimina, al pie de una canal zigzageante que penetra por varios recintos pequeños en los cuales discurren otros canales, todos ubicados en un declive que termina en explanada, creemos que pudo ser un centro ceremonial ligado al culto del agua. actividad que integraba un ritual vinculado a la religión Inca, dado el carácter agrario de la subsistencia económica estatal. Sugerimos esto en base a la similitud con el sitio cusqueño de Tambomachay, donde aparecen también canales que discurren entre estructuras, además de las distancias, extensión y tratamiento de la arquitectura. Respecto a la galería de la cima de este sector, no tenemos evidencias o asociaciones concluyentes sobre su función, salvo que ella podría indicar el inicio de una labor minera, a la que también alude el significado de su nombre como mina de oro aunque, como ya se dijo, topónimos con la terminación mina existen en los lugares huancavelicanos de Laimina y Quimina, que necesariamente no están ligados a nombres de centros mineros.

En cambio, el sector central o Tucolemisa parece que corresponde a un conjunto residencial destinado a servir como morada de los administradores del gobierno Inca, quienes estaban encargados del sistema de control político y social de la zona. Lamentablemente aparece incompleto, sea por efecto de la destrucción, o por no haber sido aún excavado. La presencia de la portada, de los recintos rectangulares erigidos en sitio plano, el trabajo y ensamblado de los paramentos, que pueden ser tipificados de estilo ciclópeo, así como la mayor abundancia de fragmentos de alfarería del Horizonte Tardío en superficie expresan, en términos generales, la posición y prestigio elevado de sus ocupantes. Se distingue, además, una habitación de mayor tamaño (Estructura A) en relación a las adyacentes (B y C), hecho que indicaría funciones distintas para cada una.

Respecto de Chuncana, que exhibe una figura a base de hoyos y canalitos interconectados, tallados sobre el piso de la roca y situado en un espacio a mayor altura que el resto de sectores, también se puede plantear una relación con actividades ceremoniales y, al mismo tiempo, considerar al sitio como un lugar de observación del espacio sideral para el cálculo astronómico. Desde este sitio se domina los diversos conjuntos arqueológicos, los territorios de la comunidad, el valle del río Ichu y las 
cumbres que rodean la zona. La preeminencia del lugar y la enigmática figura tallada, con el mismo nombre de] sitio, indicarfan que alli se realizaban actividades de observación y cálculo. Chuncana, en idioma quechua, significa jugar, pero jugar con cálculo, pues el simple juego es "pukllay". Con todo, se requiere de mayores investigaciones para llegar a obtener conclusiones firmes. Tal vez pudo haber tenido la función de ushnu o pirámide escalonada típicamente inca, pero sus caracterfsticas no coinciden con este tipo de estructuras. Hay que mencionar, por último, que hoyos y canales caracterizan a otros complejos arquitectónicos incaicos, tal como se observa, por ejemplo, en Vilcashuamán.

Los fragmentos de cerámica recuperada son en verdad escasos y ellos provienen del sector central o Tucolemisa. Esta circunstancia impide efectuar, por ahora, generalizaciones en la interpretación, pero puede ayudar en la explicación de la antiguedad del sitio y en la distinción o procedencia de sus ocupantes. De hecho, ellos expresan una ocupación tardfa, por estar asociados a estructuras de factura incaica, como por aparecer junto a tiestos de estilo cusqueño (aribalos), aún cuando proceden de la superficie. La mayoría de fragmentos son de tipo llano, de pasta uniforme y superficie de tono rojizo natural; no obstante, hay otros con engobe rojo, pero ambos comparten formas (Alfarería Llana y Alfarerfa con Engobe Rojo). Las formas tienen similitud a la cerámica que aparece en sitios como Pucara en el mismo distrito de Yauli y en Llactapata y Anccomarca, emplazados en la provincia de Acobamba, donde existen asentamientos con edificaciones circulares correspondientes a la tradición Angara. En términos generales, se vinculan a los tipos de cerámica de fases tardías que $\propto$ curren en la Sierra Cenural peruana, como Huancayo y Huancavelica y que comúnmente se hallan asociados a cerámica del estilo Inca ( Lavallée, 1967).

Si la propuesta para el caso de Uchkus es correcta, se podrfa indicar que los fragmentos más numerosos pertenecieron a los grupos nativos que concurrian al centro incaico para cumplir con las tareas tributarias exigidas por el gobiemo del Tahuantinsuyo. Un fragmento con pintura de una línea blanca sobre la superficie natural podrfa estar vinculado al estilo Mantaro, también de una fase Tardía de la zona. Los restos de alfarerfa Inca, aunque son' claramente de este estilo, por su tamaño y carencia de ornamentación no pueden ser asignados a una determinada modalidad imperial. Al respecto, se conoce que la alfarería Inca se halla distribuida en la zona de Castrovirreyna y Huaytará (Matos,1960) y se observa en muchos sitjos de las provincias huancavelicanas de Acobamba y Angaraes, como también ha sido bien identificada en las aldeas Asto (Lavallée y Julien, 1985). Esa distribución señala el amplio dominio del estado Inca entre los antiguos pueblos de Huancavelica, como ya se ha opinado, corroborado por el estudio de los documentos coloniales (Espinoza, 1973:11). Lo que aún no se ha dilucidado es el grado de influencia que pudo tener en la producción alfarera nativa, pues no se han encontrado al fares AngaraInca, como sí ocurre en los estilos Chimú-Inca o Chancay-Inca, para citar sólo dos ejemplos de trasculturación que expresan el fuerte impacto del Tahuantinsuyo en esos estilos locales. Para el caso de Huancavelica no es todavfa posible determinar este proceso, aún cuando se ha informado que en la producción alfarera Asto hay variaciones en el cuello de las tinajas que se tornan más acampanuladas, pareciéndoce a los arbalos, y también por el uso de engobes más oscuros (Lavallé, 1983:39). Entre los grupos Angara, fueron los del curacazgo Hanan Angara los que estuvieron sometidos a mayor presión y agresión por parte de los Incas (Favre, 1983-1985). Sin embargo, por la carencia de investigaciones arqueológicas en este sector, resulta aín prematuro evaluar el impacto extranjero en el área. El hecho de no haberse encontrado una clara mezcla de estilos locales con lo Inca, puede indicar la fuerza de la identidad Angara que, haciendo gala de su nombre -en quechua significarfa águila-, vivieron encaramados en sitios altos y bien protegidos. defendiendo sus territorios. Por esto, es factibje pensar que hayan entablado alianza con los curacazgos de Ayacucho y Apurímac, integrados militarmente en la confederación de los Chanca, para enfrentar la expansión de los quechuas del Cusco de la que, sin embargo, salieron derrotados.

Por todo lo expuesto, debemos mencionar que para el departamento de Huancavelica no sólo habría que considerar a Huaytará e Incahuasi como típicos emplazamientos del estilo Inca, sino también a Uchkus, aún cuando las fuentes etnohistóricas no hayan ofrecido referencias sobre su existencia.

En cuanto a la conservación y defensa del complejo arqueológico, es preciso señalar que este sitio se encuentra en peligro de destrucción, pues se observan excavaciones clandestinas en Qorimina y en Tucolemisa, afectando parte del contenido cultural de estos sectores. Por lo tanto, se requiere hacer levantamientos topograficos, reconocimientos sistemáticos del área, delimitación del complejo y, desde luego, excavaciones cientificas como tareas previas a la puesta en valor. Todos estos trabajos deben tomar en consideración a la comunidad campesina en cuyos terrenos se hallan los vestigios, pues esta población deberfa ser la primera en participar activamente en la protección de estos bienes y, si fuera el caso, beneficiarse de la promoción turística del sitio. La construcción de un museo de sitio es indispensable para la difusión de la historia del lugar. Se hace necesario el apoyo de proyectos y estudios de mayor amplitud. orientados a esclarecer y definir los aspectos arqueologicos y la función de cada sector del complejo, 
en el contexto de la sociedad local, así como en el engranaje de las instalaciones estatales del Tahuantinsuyo.

\section{CONCLUSIONES}

1. Según las exploraciones realizadas hasta el presente, el centro arqueológico de Uchkus no fue edificado sobre otros restos arquitectónicos locales, sino en un espacio libre, elegido para el asentamiento de los funcionarios al servicio del Tahuantinsuyo.

2. El conjunto, por el estilo arquitectónico, representa un establecimiento correspondiente al perfodo Inca. ubicado en territorio limítrofe entre los curacazgos de la unidad sociopolítica Angara, extendidos antiguamente por las actuales provincias de Huancavelica, Acobamba, Churcampa y Angaraes. Dicho emplazamiento, no centrado en el núcleo del grupo principal de ellos, indicaría la carencia de un gobiemo centralizado entre los Angara cuando se produjo la conquista Inca.

3. La naturaleza de los monumentos reconocidos evidencia tres sectores definidos con funciones específicas de lo que habrfa sido un núcleo uthano, proyectado como enclave del estado Inca entre los grupos Angara y destinado al control y dominio de los nuevos territorios allí conquistados.

4. E! estudio de los restos alfareros, limitados por cierto, estaría reflejando la presencia de pobladores nativos representados por los alfares locales y foráneos, poseedores de la vajilla del estilo cusqueño. Es evidente la ocupación de la zona por funcionarios de la administración estatal del Tahuantinsuyo.

5. Las dimensiones del sitio, el poco número de las edificaciones, la menor complejidad de los sectores y el acabado de los muros, manifiesta una jerarquía inferior a otros establecimientos incaicos como Vilcashuamán y Huaytará. Por otro lado, el patrón urbano de Uchkus difiere completamente del correspondiente a los poblados nativos Angara, sin duda de factura incaica.

6. Para el conocimiento historico de la intervención incaica en el departamento de Huancavelica, no sólo debe considerarse a Huaytará o Incahuasi como ejemplos únicos de asentamientos construidos bajo el régimen estatal Inca, sino también al complejo de Uchkus.

7. Es preciso reiterar la necesidad de que se amplien las investigaciones arqueológicas y que se proyecten obras de puesta en valor del complejo, teniendo en cuenta el interés y los problemas económicos de la comunidad campesina de Uchkus.

\section{Nota:}

' Entre los meses de Abril y Setiembre de 1995 el Instituto Nacional de Cultura de Huancavelica ejecutó labores de escombramiento y excavaciones en el sector central (Tucolemisa) de Uchkus. Los trabajos tuvieron una duración de 13 días (7 de Junio; 8,14,15 y 21 de Julio; $3,6,11,18,29$ y 30 de Agosto; 1 y 8 de Setiembre), tiempo en el que se extrajo aproximadamente 21 toneladas de materiales que cubrian dicho sector, según informa el folleto editado por el mismo INC de Huancavelica (INCHuancavelica, 1996).

El día 5 de Julio de 1996, visitamos la zona de Uchkus juntamente con los arquélogos Dr. Federico Kauffmann y Carlos Chaud Gutierrez, por invitación del INC-Huancavelica para observar el complejo y los trabajos realizados. Lo que pudimos observar es que se habja escombrado y excavado el sector central, quedando al descubierto casi todo el conjunto con la consiguiente aparición de nuevas estructuras que lógicamente no figuraban cuando lo visitamos en 1994. Las deducciones contenidas en el presente informe se basan en los escasos recintos que observamos en esa oportunidad y que aparecen en el plano aquí publicado. Sin embargo, mantenemos nuestra opinión en el sentido de haber sido este sector central, el núcleo residencial para quienes lo ocuparon en tiempos antiguos, aunque la aparición de las nuevas estructuras evidencian una mayor complejidad en la distribución de los espacios y que debieron cumplir, sin duda, funciones distintas. Lamentablemente, no existen registros del contexto excavado ni datos de la procedencia de algunos restos conservados en el local del INC-Huancavelica (unos cien tiestos, aproximadamente una docena de herramientas de piedra y tres objetos laminados de metal). También se observa en la superficie del referido sector excavado, centenares de fragmentos de alfareria, numerosos restos de objetos de piedra como manos y morteros, algunos huesos -al parecer de animales-, dejados como resultado del escombramiento y zanjeo del sitio. Entre los fragmentos cerámicos observados en el local del INC-Huancavelica vimos algunos de tipo Inca, un cántaro de tipo Angara y tres fragmentos vidriados evidentemente de época colonial, lo cual sirve para señalar la presencia hispana en el sitio. Pero es responsabilidad del INC de Huancavelica y Lima explicar los resultados de las excavaciones realizadas en el año 1995.

\section{BIBLIOGRAFIA}

\section{ESPINOZA SORIANO, Waldemar}

1973 "La coca de los Mitmas Cayampis en el Reino de Ancara, Siglo XVI". En: Anales Cienrificos de la Universidad del Centro del Perí, No.2, Huancayo. 
FAVRE, Henri

1983-85 El Mundo Andino en tiempos de Bolívar. Los Asto entre 1780 y 1830 . En: Revisea del Museo Nacional, Tomo XIVII. Lims- Penú.

GONZALES CARRÉ ENIique; Jarge COSMÓPOLIS A. y Jorge LEVANO

1981 La ciudad Inca de Vilcashuamón. Universidad Nacional San Cristóbal de Huamanga. Ayacucho.

\section{INC-HUANCAVEUCA}

1996 "Uchkus-Incañán. Testimonio de su pasado y su presente". En: Ediciones Warka-Willka. Órgano de expresión del Mundo Andino de Huancavelica, Año 11, No. 16. Junio. Huancavelica.

\section{JMÉNEZZ DE LAESPADAMarcos}

1881 Relaciones Geogndficas de Indias. Tomo I.

\section{KENDALL, Ann}

1976 Descripción e Inventario de las formas arquitectónicas Inca En: Revista del Museo Nacional Tomo XIIX.Lima

\section{LAVA UEE Daniele}

1967 Types Céramiques des Andes Centrales du Perou. En: Journal de la Societé des Americanistes, T.56.

1973 Estructura y Organización del hábitat en los Andes Centrales durante el Perfodo Intermedio Tandí. En: Revista del Museo Nacional, Tomo XXXI, Lima

LAVAI.LEE,Daniele y Michele Juiien

1983 Asto:curacazgo prehispánico de los Andes Cenirales. IEP. Lima

MENZEL, Dorothy

1967 "The Inca Occupation of the South Caast of Peru".En: Peruvian Archaeology. Selected Readings. Peek Publication.

\section{MATOS MENDIETA, Ramiro}

1959 Exploraciones Arqueológicas en Huancavelica. Tesis para optar el Grado de Bachiller en Humanidades. Facultad de Letras. UNMSM. Lima

1960 Informe sobre Trabajos Arqueológicos en Castrovimeina, Huancavelica. En: Antiguo Perí Espacio y Tiempo. Edit. Juan Mejí Baca. Lima

1994 Pumpu. Centro Administrativo Inka de Puna de Junńn. Editorial Horizonte.Lima.

\section{MORRRIS, Craig}

1973 Establecimientos Estatales en el Tawantinsuyo: Una estrategia de Urbanismo Obligado. En: Revista del Museo Nacional. Tomo XXXXX.Lima

PROTZEN, Jean Pierre

1993 Inca Architecture and Construction at Ollantoylambo. Oxford University Press. New York.

ROWE, John

1944 An Introduction to the Archeology of Cuzco. En: Papers of the Peabody Museum of Archaeology and Eshrology. Vol. XXVII, No. 2. Cambridge. Mass.

1946 "Inca Culture at the Time of the Spanish Conquest". En:Handbook of South American leddians. James H. Steward II, editor, pp.183330. Washington D.C., Bureau of American Ethnology, Bulletin 143.

\section{RUIZ ESTRADA, Arturo}

1995 Los monumentos arqueológicos de Uchkus. Informe presentado al INC-Huancavelica. Manuscrito.

\section{SOTO Y MACEDO, M. Loon}

1936 Antiguo Peri. Castrovirreyna Monumental, Waytard. Ensayo y contribución a la arqueología nacional. Lima. 